\title{
Linguistic Analysis of Selected TV Cartoons and Its Impact on Language Learning
}

\author{
Muhammad Arfan Lodhi ${ }^{1}$, Syeda Nimra Ibrar ${ }^{2}$, Mahwish Shamim ${ }^{3} \&$ Sumera Naz ${ }^{4}$ \\ ${ }^{1}$ Lecturer, Higher Education Department Collegiate Wing, Punjab, Pakistan \\ ${ }^{2}$ Visiting Lecturer, Govt. Sadiq College Women University, Bahawalpur, Pakistan \\ ${ }^{3}$ Lecturer, University of Lahore, Pakpattan Campus, Pakistan \\ ${ }^{4}$ M.Phil Scholar, NCBA \& E Lahore, Pakistan \\ Correspondence: Muhammad Arfan Lodhi, Lecturer, Higher Education Department Collegiate Wing, Punjab, \\ Pakistan. E-mail: samaritan_as@hotmail.com
}

Received: May 4, 2018 Accepted: June 5, 2018 Online Published: June 21, 2018

doi:10.5539/ijel.v8n5p247 URL: https://doi.org/10.5539/ijel.v8n5p247

\begin{abstract}
The new generation is fascinated by the overwhelming exposition of media. Today, media is performing powerful role in the mental growth and emotional development of children. At the very first stage of cognitive development, children copy the words and expressions used in their surroundings. Cartoons and language used in them directly affect cognitive and linguistic development of children. The present study dissects the linguistic patterns and ideologies used in cartoons shown in Pakistani media. It further attempts to overlook the impact of linguistic features of cartoons on language learning propensities of children. The study adopted mixed method research design by following qual-quan approach. The linguistic analysis of the cartoons was done qualitatively whereas its impact on children's language was measured through quantitative way. 100 students and 100 teachers were selected to determine the sample by applying random sampling technique. Self-developed questionnaire was used to collect data from the respondents. The collected data shows that cartoons are source of education, entertainment and information for children. Children can improve their language competencies by watching cartoon. However, students were found using many Hindi words in their daily conversation. Linguistic benefits of cartoon language collide with the cultural threats faced by a large number of parents. The findings of the study recommend that children should be shown level oriented and culturally specific cartoons so that students may get maximum linguistic benefits from them.
\end{abstract}

Keywords: language used in cartoons, cultural and media war, children language, language learning

\section{Introduction}

Linguistic analysis means the description of the language with regards to its morphologic, syntactical and semantic structure. The new generation of the world is certainly fascinated by the digital media as they are born and being raised in an environment which remains overwhelmed and obviously dominated by the technological explosions from the last two decades. Smart phones, I-pads and internet are accessible 24/7 to even 3 or 4 years old children. The purpose of all these technologies is to keep children involved and provide them information and entertainment. There is no doubt that cartoons are most entertaining aspect of childhood. We have all grown up watching cartoons like pink panther, Sesame Street, woody wood pecker. All these cartoons were less violent and more entertaining and informative. On the other side, there are more educationally oriented cartoon programs like, Dora the explorer sesame street john.

On the down side it is very surprising to know that some cartoons harm students' growth process. We can see our children imitating the violent gestures and repeating vocabulary from Ben 10, the Simpson and Bheem etc. The American academy of child and adolescent psychiatry (AA Cap) says that children who show violence in their behaviour, it is because of what they see. We should encourage young students to watch cartoons that are informative and enhance their learning. Comic cartoons are integral part of children's life. We can't avoid the negative effects of digital media; however we can adopt certain measures to use it positively and to engage our students by helping them grow into moderate, intellectual and cooperative individuals rather than fall victim to catastrophes of unsurprised and unlimited cartoon language. 


\subsection{Statement of the Problem}

To what extent cartoons are playing positive or negative role? This is the problem that this study focuses its attention. There is no doubt that cartoons are means of entertainment, education, and information from educational point of view, we should encourage children to watch cartoons and comics as educational cartoons increase children's language proficiency and linguistic abilities. English is rated as the second language for Pakistani a child that's why they feel lot of difficulties in writing and speaking this specific language. So by watching cartoons, they have the chance to improve the English language. By watching cartoon, they know the right accent of words. Cartoons can be the best resource of developing their linguistic competencies and improving their art of communication. But all these are possible when children watch cartoon which are scrutinized by parents.

Cartoons sometime misinform the children in real life as is the case of Pakistani social and cultural scenario is concerned. The language and culture shown in cartoons directly trigger the neuro-cognitive framework of students' brains. However, there lies a lot of diversity in seeking or gaining positive or negative impact of these cartoons. Some cartoons are informative and full of education like Dora the Explorer, Sesame Street, Mena Ki Kahani etc. but on the downside, there are varieties of cartoons which harm student's growth process. Cartoons like Ben 10 and Ninja Turtle create violent gestures in students. It is understood that we can't avoid digital media but it is our duty to watch out kids whether they are using this technology positively or the otherwise.

\subsection{Research Objectives}

1) To find out the linguistic features in the language used in cartoons.

2) To check the impact of cartoons on student's writing skills.

3) To find out how other languages are influencing the student's speaking ability.

4) To identify the means in which Pakistani values are mis/represented.

\subsection{Research Questions}

1) What kind of linguistic features are used in the language of cartoons?

2) What are the advantages and disadvantages of language of cartoon on students' writing skills?

3) What is the impact of cartoon language on students' speaking skills?

4) To what extent cartoons represent / misrepresent Pakistani culture and society?

\subsection{Significance of the Study}

The language plays important role in our life and in our society. Language is the way of expression. We express our ideas, feelings and emotions through language so the importance of language can't be denied. This study may prove helpful for those who want to improve the language proficiency among the children through effective exposure of cartoons. Moreover, this study is significant for the better understanding of the role of cartoon language. The language of cartoon use special kind of linguistic features, stylistic and literary device to educate, entertain and to fascinate the students. This study is helpful for the teachers and parents to keep a check on the media and cartoons being shown to children at a very tender age.

\section{Literature Review}

\subsection{History of Cartoons}

The first motion picture was made in the late eighteenth century by using animation cartoon movies are made in starting a funny film was prepared for amusing and educating the children (Thompson, 2010). At the initial stage, cartoons were in short form. The reason is that people like these shorts in the movie theatres before they see feature film. After that the cartoons were shown on TV and it got a longer time. Today, cartoons have become integral part of children's life. They watch cartoon shows keenly. When cartoons were presented on TV, it got longer time. The simple meaning of cartoon is drawing a sketch in newspaper or in magazine. The exact meaning of "cartoon" comes from the Italian word "carton" which means "big paper" and it is used for drawing or art work which is made on paper. The real meaning of cartoon means large size sketch made on paper. During the sixteenth century, cartoons were first used for fresco painting peter Paul Rubbers is one of the renowned artist who showed a collection of cartoons for tapestries.

\subsection{Types of Cartoons}

There are five types of cartoons which are very famous: 


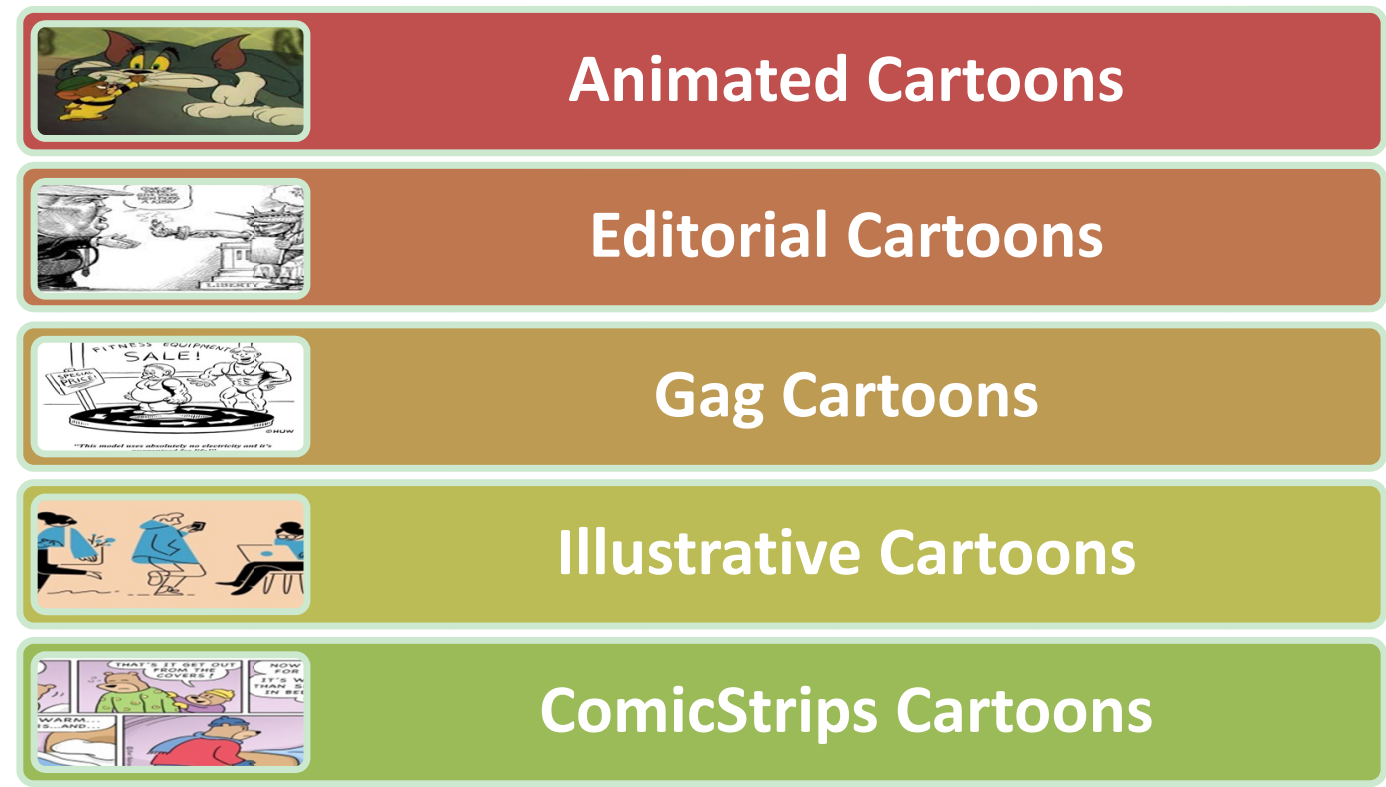

Figure 1. Types of cartoons

\subsubsection{Animated Cartoons}

Animated cartoons are produced by recording of still pictures about people and objects situated in different position of gradual movement when it played all these none moving pictures move fast. They give an impression of unbreakable movement. The word animation did not remain limited but it also apply on films, computers, and videos which are conventionally composed in shape of series of sketches, photographs and are drawn on papers. So, cartoon means short animated work which is funny in nature.

\subsubsection{Editorial Cartoon}

Another type of cartoon which is called editorial cartoon, it is used for political purpose. Editorial cartoons use symbol. The cartoonist uses symbol to convey his message. So far a Dove is symbol of peace and Ass a symbol of foolishness. For example a hungry ruptures is a symbol to gallop all things. This symbolizes just corruption galloped big companies. In animated cartoons John Bull is considered the figure of kingdom. Animation means a picture which is created by the series of pictures. It means series of pictures so fast that it gives the image of moving picture. This term animation brought a great change in the field of film, video and computers.

\subsubsection{Gag Cartoon}

It shows a lot of contradiction from political point of view. It has been used for many purposes. Gag cartoons consist of single drawing and used in newspapers, greeting cards and magazines. Most renowned artist is Gray Larson, Thurber James and Peter Arno. Chuck Johns says about Winsor McKay that he is not sure who is the first artist in the field of Gag cartoons but the name of Winsor McKay is very important who work in this ground.

\subsubsection{Comic Strip}

Comic strips means strip cartoon. Mostly, comic strips are either presented in series or alone. They are connected with the story sequence and remain continue daily or weekly. This type of cartoons use in newspapers and magazines on daily basis, their character becomes famous among the people. This type of cartoon characters is popular that people can recognize it quickly.

The famous story like "The Phantom" which is about the adventure of the person comes daily on news papers. People are eagerly waiting for this story every day. Mostly news about current affairs is related to comic strips. Many political cartoons are in the form of comic strips because the editor wants to tell the story about life of the famous politician daily. This type of stories attracts people's attention and they want to know about the life of their famous politicians. Sometimes, the editor of the newspaper represents animals to convey his message.

\subsubsection{Illustrative and Advertising Cartoons}

This type of cartoon related to advertisement. The purpose of this type of cartoon is to draw attention of the viewers and keep them busy about advertisement. This cartoon's purpose is not big but they have little meaning 
by themselves. They just draw attention that what is written on school book and on advertisement. It has no double meaning and personification like political and other type of cartoons. It used for similar purpose as its function to high light the many key point in which was written on school books.

\subsection{Impact of Cartoons on Children's Learning}

As everybody knows that cartoon is favourite thing for children. They feel great by watching cartoons. Even children when they are infants, at the age of five or six months, they started to watch cartoons, in this way, they become a good viewer of cartoons. Because they sit in front of television, they show great happiness even they started to recognize their favourite cartoon character. This thing create problem when children watch too much cartoon. Famous proverb is that excess of everything is bad. Today, children are addicted to watch cartoons.

The cartoons marketing make use of this weakness of the children. Because children are innocent they do not know that everything must have some limits otherwise it will be dangerous to their mind and health. We should create awareness among children that balanced is the name of life. They should watch cartoon, no doubt cartoons give entertainment and opportunity to relax the mind of children. It is the responsibility of the parents to make the life routine of their children balanced. It is not a fault of children that today they are addicted to watch cartoon all the time but it is the fault of parents who make their life to do so.

\subsubsection{Psychological and Mental Impact of Cartoons on Children}

The proverb is "A man does what he sees". This formula is definitely applicable on children. What kind of cartoon content they watch, their mental and psychological condition will develop like this. Today, cartoon's content is full of violence and terrorism. When children watch the literature of violence, how can we expect from them that they become a good citizen, dislike guns and violence? When they watch their favourite character is playing with guns and booms. Definitely they think about it right because whatever the hero does is right thing. The research shows that most of the students or children feel inclination to play with guns. That's why the toy guns are favourite toy of boys. Cartoons are not only change children's behaviour but also changing their language. Children's behaviour are changed; they do not remain innocent what they were in past.

A child of today is much more intelligent, clever, and sharp than the past. It would not be wrong to say that media and cartoon has snatched his innocence. The research says that watching too much cartoons create a mental and psychological emotional problems. Unfortunately, cartoon shows glorify the use of guns and violence. When these entire element will be the content of cartoon. How can be we hopeful about the good and constructive growth of the children. Parents should ensure that the content of what their children is watching is supportive and contributing to their health state of mind or not. Today, the mental and psychological growth of children is influenced by the wrong content of cartoons. It is the duty of parents to avoid this danger and take initiative steps to stop mental and psychological disadvantages.

\subsection{Linguistic Features and Language of the Cartoons}

Linguists and educationists agree on the point that students learn a lot by watching cartoons and it has deep impact on their learning. In past, students were who can speak excellent English. It was considered that he must have been to English university. According to Clark (2002) from pedagogical point of view the importance of cartoon is very valuable. Cartoons give the learner atmosphere in which he finds himself engage and create the scene to enhance his abilities and his listening and speaking abilities unconsciously increased. Doring (2002) argued that there is no doubt that there is a great effect of the language of cartoons on learning. He further said that learner create his oral capabilities so that he answer the question. This make is learner's brain productive. He can do something by himself. He knows to use his brain. This thing gives him a confidence and makes his work interesting and valuable. Another study conducted by Rule and Auge, 2005.

The previous results show that for language learning student give importance to cartoons because cartoons motivate them give new ideas new way of learning they can improve their speaking and listening skills research shows all linguists are agreed on this point students who was watch cartoons, they have chance to make them confident. They can improve their language skills and gain higher goal of their future. Baharam and sin (2012) carried out a quantitative research and find out the result that the students these who are weak in their studies and they are slow learner in acquiring language proficiency. Linguists suggest for them watching cartoon would increase their language ability. Students unconsciously observe the sentence and dialogue of the cartoon and try to adopt their accent.

One of most striking quality of cartoon is repetition. In cartoons characters repeat their dialogue, though the repetition of words sentences. Students have a chance to correct and improve language proficiency. Moreover students succeeded to achieve the target language (Hague 2015) Linguists says when a student adopt new 
language it effect on his personality and ultimately change his cultural values. This change is called mirroring. When children see cartoon, obviously positive characters are liked by them. And they went to adopt their personality their dressing, ways of spoken language. They discuss their humour, values, adventure. For learning a language positive atmosphere is essential for a learner. Without this a learner is not to able learn anything else. (Aboudan 2013). There is a very interesting element in cartoons. Learner learns the language without knowing that he is learning the language. This positive element reduces the pressure of being aware learning something. In this way, student learns a lot without pressure of learning. For example a child revise different words which he listen from the cartoon which remain unconsciously remain in his mind. This is called "suggestopedia".

It means a process in which a learner learns the foreign language in delightful and playful manner. According to Bahrani and Sims (2012)'s suggestopedia, repetition plays important role in the process of learning. For example, one student tells his own childhood's experience when he was a child, he used to watch English cartoons when he did not understand anything he revised that segment again and again. This method of watching cartoons makes my language proficiency better. These are also many students who have good pronunciation just because of observing, listening the language of cartoons. Linguists come on this conclusion; language acquisition would possible and effective by listening and watching cartoons.

\section{Research Methodology}

The purpose of this study is to evaluate the impact of animated cartoons on language learning of the children. The research design was exploratory in nature. The mixed method approach was applied to gather, analyze and interpret the data. The qualitative methodology was used to analyse and interpret the information gathered from cartoon programs, whereas quantitative approach was applied to analyzed data obtained from students and teachers. The population of this study comprised of the animated cartoons shown at Pakistani TV channels. However, only one cartoon program "Chhotta Bheem" was taken as accessible population of the study. Furthermore, 100 teachers and 100 students at elementary level were selected as sample of the study. The sample for this research was selected from the students and teachers of govt. Schools of Bahawalpur district. Proportionate random sampling technique was used to determine equal number of male and female participants. On the other hand, selected lines from 50 episodes of Chota Bheem cartoons were selected for content analysis by using purposive sampling technique. Data was collected by administering questionnaire among students and teachers. It consisted of 45 items in which respondents were asked about their favourite cartoon programs, frequency of watching cartoons, and the impact of cartoons on learners' academic life. The validity and reliability of questionnaires was ensured in the pilot testing phase. The cronbach alpha level of students' and teachers' questionnaires was .83 and .79 respectively. After obtaining the acceptable level of reliability, questionnaires were administered among the participants of the study. Data collected from cartoon programs was analyzed through the technique of content analysis. However, data collected from questionnaires was analyzed by using descriptive statistics technique to measure the frequency, percentage and mean value of the responses. The study was delimited to the govt. and private schools of district Bahawalpur.

\section{Findings and Discussions}

This section deals with the interpretation of data collected from cartoon analysis. Students' favourite television cartoons were selected for linguistic analysis and it is observed there is great difference between the language used in them and the language spoken in Pakistani society.

\subsection{Interpretation of Data obtained Through Content Analysis}

Table 1. The data collected from cartoons

\begin{tabular}{lllllllll}
\hline \multicolumn{2}{l}{ Royal relations and state affairs } & \multicolumn{2}{l}{ About the Universe } & \multicolumn{3}{l}{ About greetings } \\
\hline English & Urdu & Hindi & English & Urdu & Hindi & English & Urdu & Hindi \\
\hline Prince & shahzada & Rajkumar & Earth & Zameen & Prithvi & Thank you & Shukria & Dhanewat \\
Princes & Shahzadi & Rajkumari & Cloud & Badal & Perbat & Blessing & Slam & Pernam \\
Dress & Libass & Poshak & Moment & Lumha & Sameh & Congratulation & Mubarak & Badahi \\
Invitation & Dawatnama & Neuta & Moon & Chand & Chanderma & Well Come & Khush-Amdeed & Swagut \\
\hline
\end{tabular}

The table shows that there are many words being used by students in their everyday language. Many Hindi words are found in their language which is affecting badly their native language and has deep impact on them. Moreover, cartoons are consciously promoting Hindi language to new generation. Students are using many Hindi words about the universe in their everyday language. This shows that Hindi language words are being promoted 
by cartoons. "Chaya", "Perbat" or "Sameh" are mostly common words in students' language. This shows that cartoons have deep impact on them. It is observed that students were using greetings in Hindi language as compared to Urdu language now-a-days. Textual and contextual analysis of cartoon language shows that cartoons are not only promoting Hindi language but also Hinduism. "Dhanewat", "Swagut" are most commonly found words in student's language. The data displayed that there Hindi words are different from those words which are found in native language. The data also revealed that now-a-days majority of students were found using these words in the spoken language. They called their 'family' as 'Periwar'. These words are now being used by students in their everyday language. They were found of reporting their family relation in Hindi like, some students called their sister as "Didi" instead of "Behan". This thing shows that Hindi Cartoons are promoting Hindi culture with the mean of Cartoon.

\subsection{Interpretation of Data Collected from Students' Questionnaire}

This section deals with the interpretation of data collected from students' questionnaire. The data was collected from to know their perspective about their favourite television cartoons.

Table 2. Questionnaire

\begin{tabular}{|c|c|c|c|c|}
\hline Statement & Institutions & Yes & No & U.D \\
\hline \multirow[t]{2}{*}{ Watch Cartoons } & Private & 38 & 10 & 02 \\
\hline & Govt. & 35 & 13 & 02 \\
\hline \multirow[t]{2}{*}{ Enjoy comic cartoons } & Private & 30 & 16 & 04 \\
\hline & Govt. & 34 & 13 & 03 \\
\hline \multirow[t]{2}{*}{ Spend excessive time in watching cartoon } & Private & 19 & 29 & 02 \\
\hline & Govt. & 16 & 30 & 04 \\
\hline \multirow[t]{2}{*}{ Prefer watching cartoons than physical activities } & Private & 20 & 26 & 04 \\
\hline & Govt. & 23 & 25 & 02 \\
\hline \multirow[t]{2}{*}{ Cartoons are means of education and entertainment } & Private & 29 & 15 & 06 \\
\hline & Govt. & 35 & 12 & 03 \\
\hline \multirow[t]{2}{*}{ Indian cartoons influence your linguistic preferences } & Private & 38 & 11 & 01 \\
\hline & Govt. & 39 & 09 & 02 \\
\hline \multirow[t]{2}{*}{ Cartoons spoils moral, social and lingual values } & Private & 40 & 07 & 03 \\
\hline & Govt. & 45 & 02 & 03 \\
\hline \multirow[t]{2}{*}{ Student's violent behaviour due to violence in cartoons } & Private & 39 & 10 & 01 \\
\hline & Govt. & 46 & 03 & 1 \\
\hline \multirow[t]{2}{*}{ Ben Ten gives the students hope and confidence } & Private & 29 & 16 & 05 \\
\hline & Govt. & 35 & 13 & 02 \\
\hline \multirow[t]{2}{*}{ Cartoons give new ideas to students } & Private & 32 & 14 & 04 \\
\hline & Govt. & 29 & 20 & 01 \\
\hline
\end{tabular}

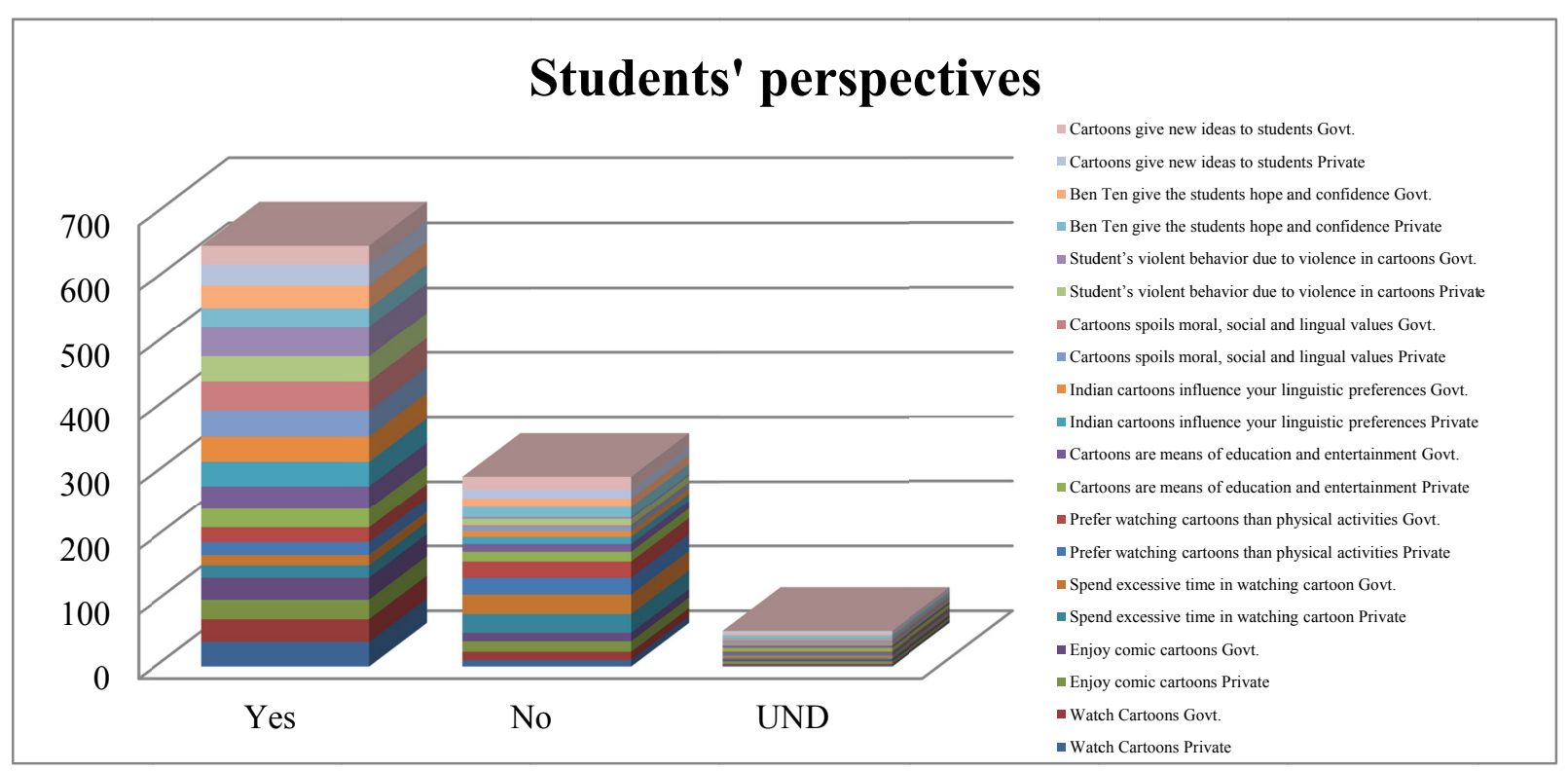

Figure 2. Students' Perspectives about effect of cartoon programs 
Table 2 and demographic information displays the results collected from students' questionnaire. A questionnaire was used to collect data from students in order to know their perspective about their favourite television programs like cartoon. In the first section they were asked to share their view about watching cartoons. Majority of respondents replied in affirmation that they watch cartoons. Moreover, they also claimed that they enjoy watching cartoons and spend their most of time in watching cartoons. The students belong to both government and private schools. When asked to share their views about their preference between cartoons and physical activities; majority of members agreed that they prefer watching cartoons rather than playing games or other physical activities. They further added that these cartoons are the source of education as well as entertainment. The data also revealed that majority of students were greatly influenced by Hindi cartoon or those who were dubbed in Hindi language without realizing that these cartoons spoil their moral, social and linguistic values.

\subsection{Interpretation of Data Collected from Teachers' Questionnaire}

\section{PART A}

Table 3. Linguistic analysis of cartoon language

\begin{tabular}{llllllll}
\hline Item & Participants & SA & A & UND & D & SD & Mean Score \\
\hline Influence of cartoon on mother tongue & Government & 34 & 7 & 1 & 7 & 1 & 4.32 \\
& Private & 28 & 9 & 2 & 9 & 2 & 4.04 \\
Change in language due to Cartoon & Government & 25 & 10 & 8 & 4 & 3 & 4.0 \\
& Private & 20 & 15 & 10 & 2 & 3 & 3.94 \\
Spoil moral and social values & Government & 30 & 14 & 2 & 2 & 2 & 4.36 \\
& Private & 30 & 10 & 4 & 3 & 3 & 4.22 \\
Role in language learning & Government & 29 & 10 & 3 & 4 & 4 & 4.12 \\
& Private & 25 & 16 & 4 & 2 & 3 & 4.16 \\
Impact on students' mind & Government & 30 & 9 & 5 & 2 & 4 & 4.18 \\
& Private & 19 & 10 & 3 & 8 & 10 & 3.4 \\
\hline
\end{tabular}

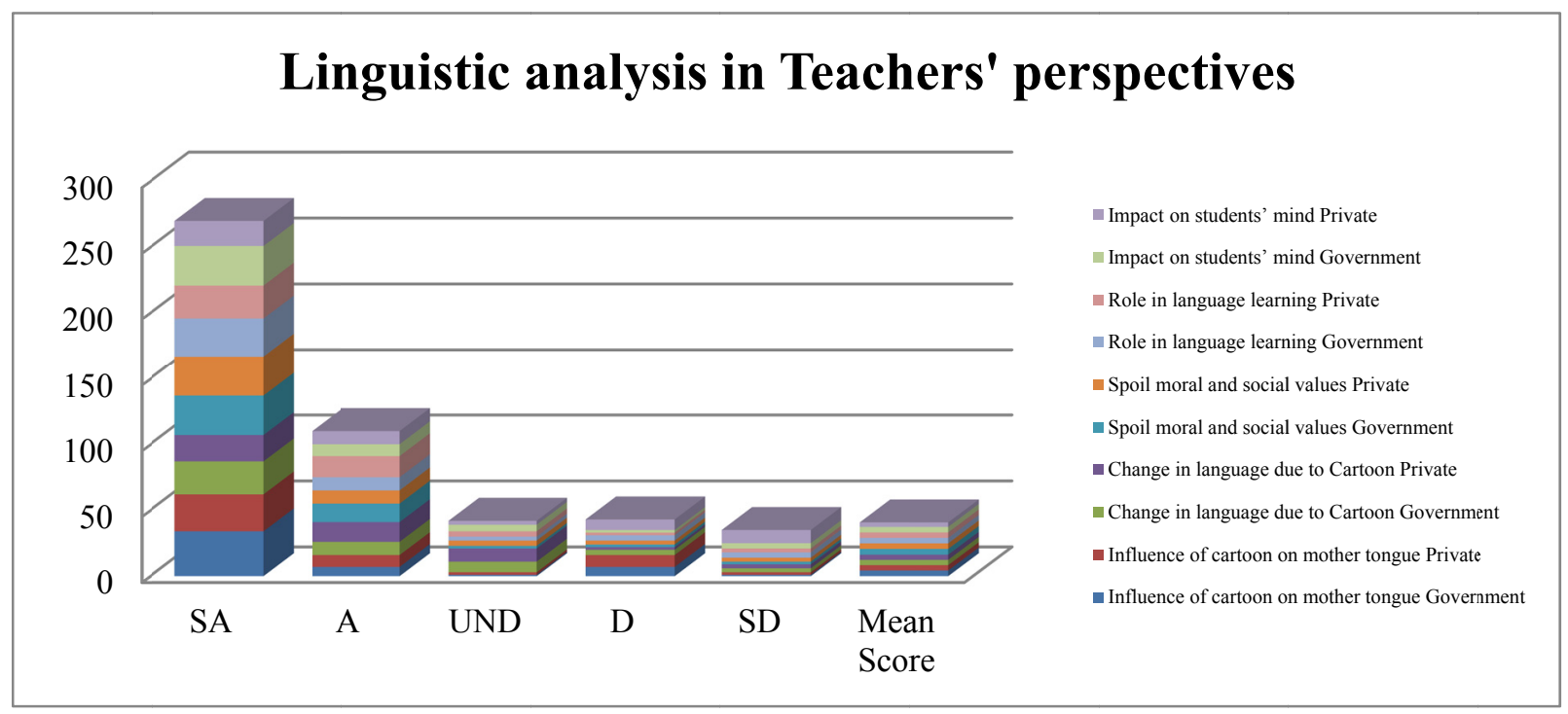

Figure 3. Teachers' perspectives about effect of cartoon programs

Table 3 and following graph interprets the data collected from teaches' questionnaire. The data displayed that majority of teachers were strongly agree with the statement that Today, our mother tongue is greatly influenced by linguistic expressions which are presented in cartoons. Moreover, teachers showed positive results towards the statement that Cartoons are not only changing student's behaviour but also changing their language. However, only few of them were disagree with the statement that Cartoon plays major role in language learning. They further stated that Cartoons dubbed with Hindi language are spoiling moral and social values because language of animated cartoon has a deep impact on the minds of students. 


\section{PART B}

Table 4. Advantages and disadvantages of the cartoon's language

\begin{tabular}{|c|c|c|c|c|c|c|c|}
\hline Item & Participants & SA & $\mathbf{A}$ & UND & D & SD & Mean Score \\
\hline \multirow[t]{2}{*}{ Effect on students' growth } & Government & 35 & 5 & 4 & 4 & 2 & 4.34 \\
\hline & Private & 30 & 13 & 3 & 2 & 2 & 4.34 \\
\hline \multirow{2}{*}{$\begin{array}{l}\text { Preference of cartoon on physical } \\
\text { activities }\end{array}$} & Government & 30 & 8 & 8 & 2 & 2 & 4.24 \\
\hline & Private & 28 & 10 & 7 & 4 & 1 & 4.20 \\
\hline \multirow[t]{2}{*}{ Cause of mental and emotional problems } & Government & 25 & 10 & 8 & 4 & 3 & 4.00 \\
\hline & Private & 26 & 16 & 2 & 4 & 2 & 4.20 \\
\hline \multirow[t]{2}{*}{ Mislead audience } & Government & 30 & 10 & 4 & 4 & 2 & 4.24 \\
\hline & Private & 34 & 5 & 6 & 3 & 2 & 4.32 \\
\hline \multirow[t]{2}{*}{ Impact of internet on students' mind } & Government & 20 & 15 & 8 & 2 & 5 & 3.86 \\
\hline & Private & 18 & 17 & 2 & 5 & 8 & 3.64 \\
\hline
\end{tabular}

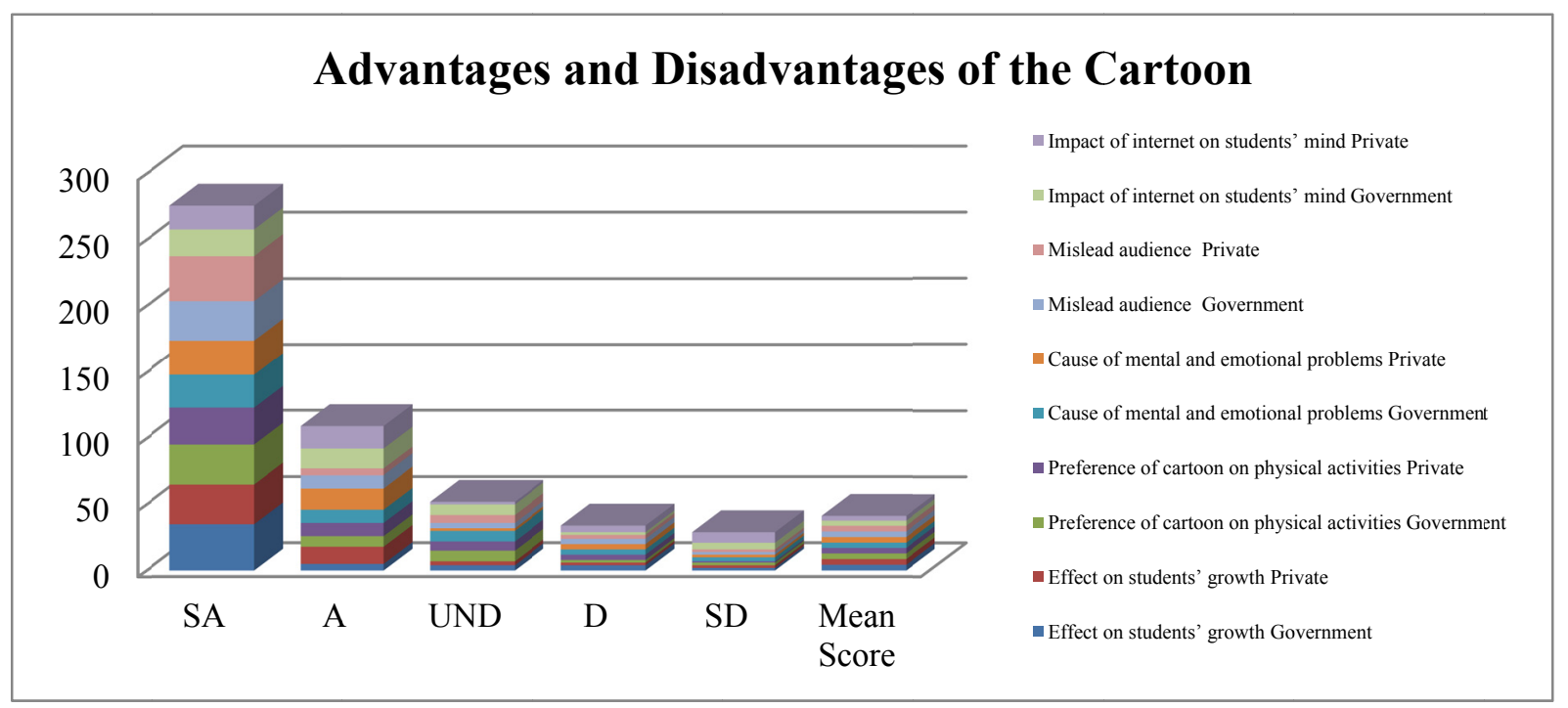

Figure 4. Advantages and disadvantages of cartoon programs for ESL learners

Table 4 and following graph interprets the data collected from teaches' questionnaire. The data shows that majority of members were agreed with the statements A large number of teacher stated that cartoons affect mentally as well as physically on the growth of students. It is observed that students prefer Ben Ten and Doremoon than physical activities that's why watching too much cartoons cause mental and emotional problems. However, many teachers stated that cartoon serves as a means of entertainment but at the same time it misinforms the students about real life. Some of them claimed that television and internet have strong impact on students. It is also observed that 78 percent of the students are attracted by the dresses of cartoons characters like Ben Ten, Spiderman etc. Moreover, student's violent behaviour leads to poor academic performance because the world of animated cartoon students enjoys the world of imagination and fantasy.

\section{Part C}

Table 5. Cartoons presenting or misrepresenting Pakistani culture and society

\begin{tabular}{|c|c|c|c|c|c|c|c|}
\hline Item & Participants & SA & A & UND & D & SD & Mean Score \\
\hline \multirow[t]{2}{*}{ Promotion of culture } & Government & 30 & 10 & 5 & 2 & 3 & 4.24 \\
\hline & Private & 30 & 9 & 8 & 1 & 2 & 4.28 \\
\hline \multirow[t]{2}{*}{ Representation of Hindu culture in Chota Bheem } & Government & 30 & 6 & 5 & 5 & 4 & 4.06 \\
\hline & Private & 40 & 6 & 2 & 1 & 1 & 4.66 \\
\hline \multirow[t]{2}{*}{ Use of Hindi in language } & Government & 35 & 9 & 1 & 2 & 3 & 4.42 \\
\hline & Private & 18 & 17 & 2 & 5 & 8 & 3.64 \\
\hline \multirow[t]{2}{*}{ No option, other than Indian Cartoons } & Government & 33 & 7 & 7 & 2 & 1 & 4.38 \\
\hline & Private & 30 & 8 & 7 & 2 & 3 & 4.20 \\
\hline \multirow[t]{2}{*}{ Part of social culture throughout the history } & Government & 38 & 5 & 2 & 2 & 3 & 4.46 \\
\hline & Private & 32 & 10 & 1 & 6 & 1 & 4.32 \\
\hline
\end{tabular}




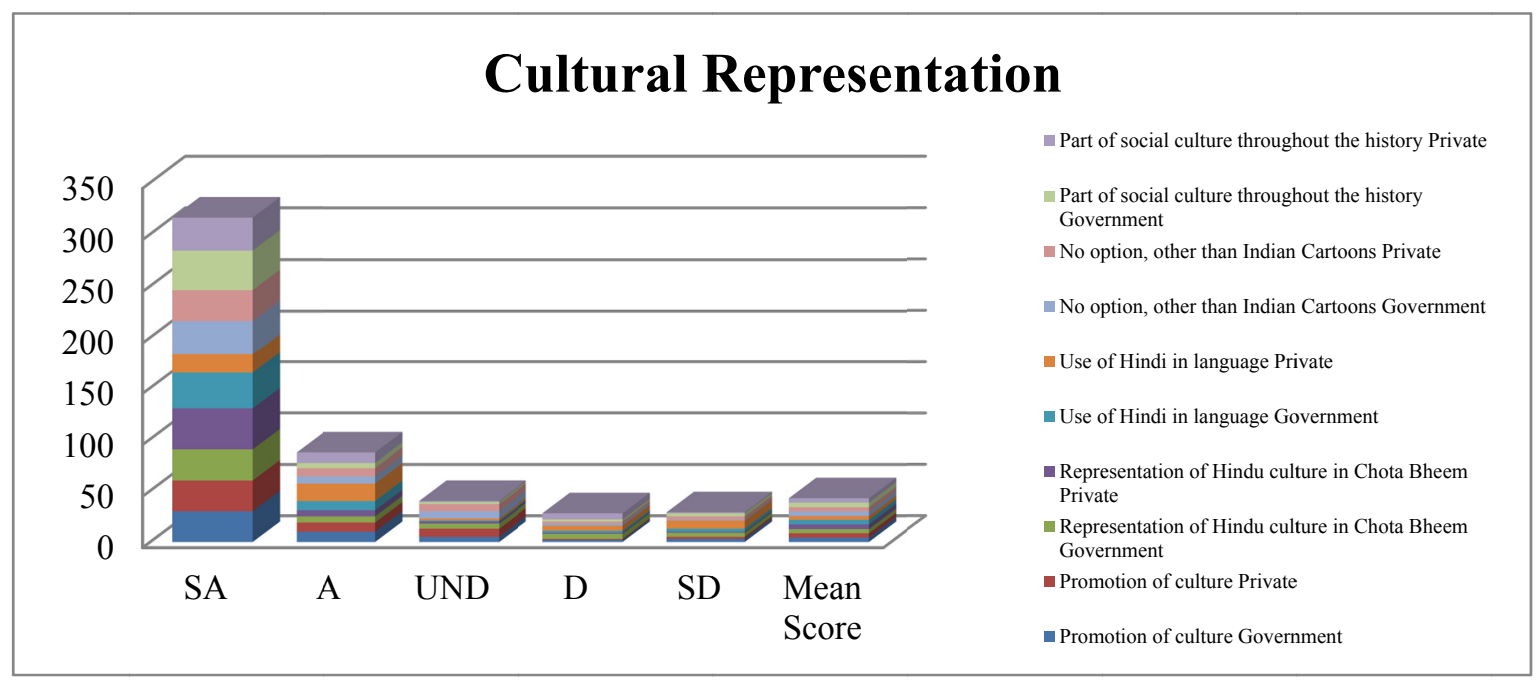

Figure 5. Cultural representation of selected cartoons

Table 5 and subsequent graph display the data collected from teachers' questionnaire. When asked about Indian Cartoons are promoting Indian Culture and Hinduism in Pakistan, majority of teachers was agreed that Indian Cartoons misguide the Pakistani students. They further stated that we can promote our culture through cartoons. However, Chota Bheem represents Hindu Society and misguides our students. Today, many students are using many Hindi words in their conversation. It is argued that 44 percent students like to buy different accessories related to different cartoon characters. Some teachers claimed that this is due to lack of Pakistani cartoons our students have no option to see the Indian cartoon. History shows that cartoons have been part of social cultural and civilization.

\section{PART D}

Table 6. Cartoon affect students' speaking skills

\begin{tabular}{llllllll}
\hline Item & Participants & SA & A & UND & D & SD & Mean Score \\
\hline Source of improving speaking skills & Government & 35 & 9 & 2 & 3 & 1 & 4.52 \\
& Private & 33 & 5 & 2 & 2 & 8 & 3.96 \\
Improvement in accent due to cartoons & Government & 30 & 9 & 6 & 4 & 1 & 4.26 \\
& Private & 28 & 10 & 2 & 8 & 2 & 4.4 \\
Deep impression on speaking & Government & 30 & 9 & 7 & 3 & 1 & 4.28 \\
& Private & 35 & 7 & 2 & 3 & 3 & 4.36 \\
\hline
\end{tabular}

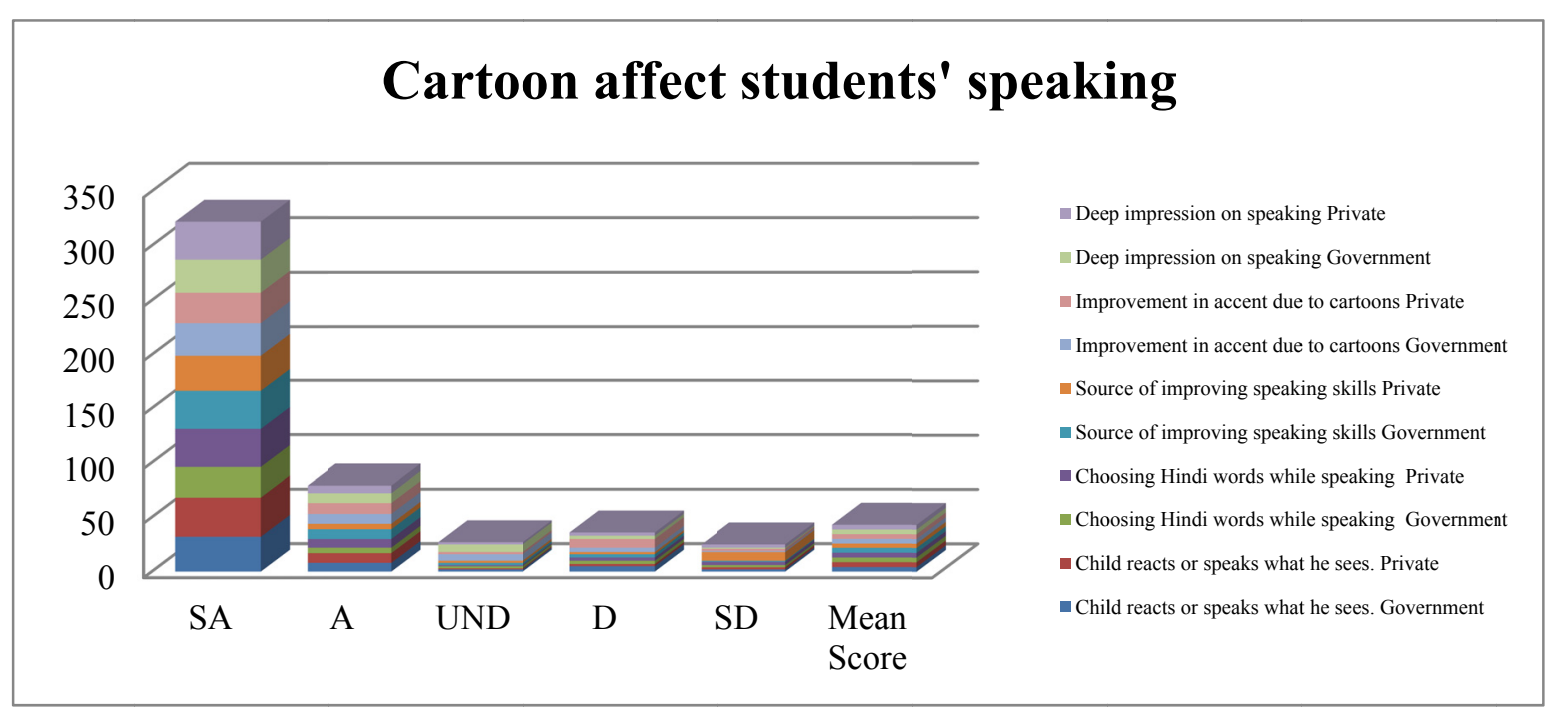

Figure 6. Linguistic representation of cartoon programs 
Table 6 and subsequent graph display the data collected from teachers' questionnaire. Research shows that child react or speak what does he see. In Pakistan, the impact of Hindi cartoons is obvious, they students choose Hindi words while, speaking. Today, Cartoons are not mere cartoon but it becomes a source of improving speaking skills. Through the accent of cartoon characters, students can improve their spoken language. The language of cartoons has deep impression on speaking skill.

\section{PART E}

Table 7. Outcomes

\begin{tabular}{llllllll}
\hline Item & Participants & SA & A & UND & D & SD & Mean Score \\
\hline Allowing educational and informative cartoons & Government & 28 & 10 & 4 & 1 & 7 & 4.02 \\
& Private & 36 & 9 & 1 & 2 & 2 & 4.54 \\
Ensuring the content of cartoon & Government & 36 & 9 & 1 & 3 & 3 & 4.56 \\
& Private & 36 & 6 & 2 & 3 & 3 & 4.38 \\
Banning Indian Cartoons & Government & 20 & 15 & 5 & 2 & 8 & 3.74 \\
& Private & 34 & 5 & 1 & 2 & 8 & 4.10 \\
Engage students into physical activities & Government & 32 & 2 & 8 & 4 & 4 & 4.08 \\
Allowing, those cartoons which improve speaking & Private & 33 & 8 & 5 & 2 & 2 & 4.36 \\
& Government & 27 & 16 & 2 & 4 & 1 & 3.8 \\
& Private & 30 & 7 & 3 & 6 & 4 & 4.06 \\
\hline
\end{tabular}

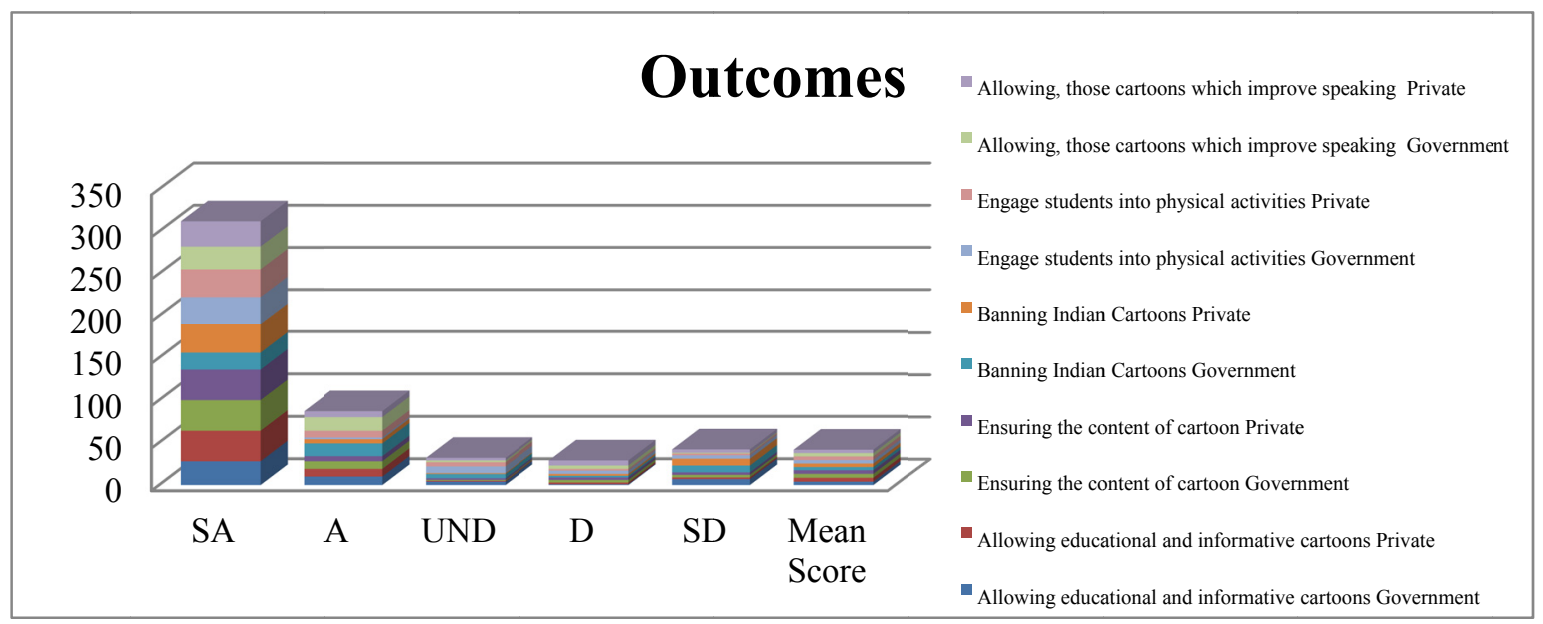

Figure 7. Suggestions and outcomes of cartoon programs

Table 7 and subsequent graph display the data collected from teachers' questionnaire. Majority of members were agreed with the statement that educational and informative cartoons should be watched. Moreover, parents should ensure about the content of what their children are watching is supportive and contributing to their health of mind. Indian Cartoons should be banned. Teachers as well as parent try to engage them in physical activities so their life routine should be balanced. Such animated cartoon movies are introduced to students which develop their speaking skill and help them in language learning.

\section{Conclusion}

There is a close relationship between text linguistics and discourse analysis which is closely connected to this field. Discourse means use of words for changing our thoughts and ideas; on the other hand discourse analysis means the study of linguistic relations with discourse, in which the linguistic structure is discussed. Positive effects of the cartoons on a child can be analyzed by few key points. Socially, positive cartoons could be used to teach a child how to control his or her temper, speak in a polite way, obey his parents, aid the old, help the poor and lend hand to the young and to work in a group without any feeling of jealousy. Speaking about the skills, positive cartoon content could teach the children how to analyze problems in scientific manner, think about acting and eve to cause a kid to love a sport. Concerning life experience, a good cartoon could be like teaching a child about dangers of life, danger of electricity, how to deal with broken arm. A cartoon hero could be a child's model for years. A child could gain pure content of good deeds and message of kind hearted from the hero. On the other hand, a violent cartoon movie could be much more dangerous for a child. It could contain content that 
would confuse the child with which he or she experiences in real life. Negative content could lead a child to doubt his or her raising, way of thinking, life style. A character with negative qualities appears on the screen as $\mathrm{s}$ hero will definitely mislead to children's abilities and destroy their mental growth. Cartoons can be used as a productive tool for learning or destructive tool as well. It is recommended that material should be checked properly before presented through cartoons. So that maximum benefit can be achieved from these cartoons.

\section{References}

Aboudan, R. (2009). Laugh and Learn: Humor and Learning a Second Language. International Journal of Arts and Science, 3, 90-99.

Anderson, C. A. (2003). The influence of media violence on youth. Psychological Science in the Public Interest, 4, 81-110. https://doi.org/10.1111/j.1529-1006.2003.pspi_1433.x

Bahrani, T., \& Sim, T. S. (2012). Audiovisual news, cartoons and films as sources of authentic language input and language proficiency enhancement. Turkish Online Journal of Educational Technology, 11(4), 56-64.

Bandura, A. (1994). Social Cognitive Theory of Mass Communication. Routledge.

Barr, R., \& Linebarger, D. L. (2010). Special issue on the content and context of early media exposure, infant and child developments. Infant \& Child Development, 19(6), 553-556. https://doi.org/10.1002/icd.716

Canemaker, J. (2005). Winsor McCay, His life and Art. New York, NY: Harry N. Abrams.

Chomsky. (2006). Language and mind (3rd ed.). New York, NY: Cambridge University Press. https://doi.org/10.1017/CBO9780511791222

Chota Bheem Cartoon Review, Cast, Bio. (2015). Retrieved on November 2016.

Christakis, D. (2009). The effects of infant media usage: what do we know and what should we learn? Acta Paediatrica, 98(1), 8-16. https://doi.org/10.1111/j.1651-2227.2008.01027.x

Clark, C. (2000). Innovative Strategy: Concept Cartoons. International Learner Strategies. Web Resource.

Doring, A. (2002). The use of cartoons as a teaching and learning strategy with adult learners. New Zealand Journal of Adult Learning, 30, 56-62.

Edwards, J. L. (1997). Political Cartoons in the 1988 Presidential Campaign. London.

Fairclough, N. (1992). Discourse and Social change. Cambridge: Polity Press.

Fairclough, N. (2003). Analyzing Discourse: Textual analysis for Social research. Cambridge.

Fetzer, S.(1994). The World Book Encyclopaedia. Cambridge.

Foucault, M. (1980). Power/Knowledge: selected interviews and other writings 1972-1977. Edited by C. Gordon Brighton. Harvester Press.

Gerbner, G., Gross, L., Morgan, M., \& Signorielli, N. (1994). Growing up with television: The cultivation perspective. In J. Bryant \& D. Zillmann (Eds.), LEA's communication series. Media effects: Advances in theory and research (pp. 17-41). Hillsdale, NJ, US: Lawrence Erlbaum Associates, Inc.

Ginman, M. (2003). Cartoons as information. Gournal of Information Science, (29), 6977. https://doi.org/10.1177/016555150302900109

Gokcearslan. (2010). Studied the Effect of Cartoon Movies on Children's Gender Development. Procedia-Social and Behavioral Science, 2(2), 5202-5207. https://doi.org/10.1016/j.sbspro.2010.03.846

Gokulsing, K. M. (2009). Popular culture in globalized India. Routledge.

Hammersley, M. (1997). On the foundations of critical discourse analysis. Language and communication, 17(3), 237-248. https://doi.org/10.1016/S0271-5309(97)00013-X

Hassan \& Daniyal. (2013). Cartoon Network and its Impact on Behavior of School Going Children. New York: Macrothink.

Klein, H., \& Shiffman, K. (2006). Massage about physical attractiveness in animated cartoons. Body Image, 3(4), 353-363. https://doi.org/10.1016/j.bodyim.2006.08.001

Kottak, C. P. (1990). Prime time society: An anthropological analysis of television and culture. Belmont, CA: Wadsworth.

Mayya, S. (2007). Integrating new technology to commerce curriculum: how to overcome teacher's resistance? The Turkish online Journal of Education Technology, 6(1), 8-14. 
Rule, A. C., \& Auge, J. (2005). Using humorous cartoons to teach mineral and rock concepts in sixth grade science class. Journal of geosciences education, 53(3), 548-558. https://doi.org/10.5408/1089-9995-53.5.548

Van Dijk, T. (1991). Racism and the Press. New York and London: Longman.

Van Dijk, T. A. (1993). Elite Discourse and Racism. London: Sage Publications. https://doi.org/10.4135/9781483326184

Zimmerman, F. J., Gilk, J., Richards, J., A., Christakis, D. A., Xu, D. X., Gray, S., \& Yapanel, U. (2016). Teaching by listening. The importance of adult-child conversations to language development. Pediatrics. Retrieved from https://pdfs.semanticscholar.org/fa62/bc816f12fc6b58496902286d05af8d1cdc25.pdf

\section{Copyrights}

Copyright for this article is retained by the author, with first publication rights granted to the journal.

This is an open-access article distributed under the terms and conditions of the Creative Commons Attribution license (http://creativecommons.org/licenses/by/4.0/). 